\title{
The role of histopathological examination of the products of conception following first-trimester miscarriage in Erbil Maternity Hospital
}

Payman Anwar Rashid*

\begin{abstract}
Background and objective: Miscarriage represents a common problem that occurs in the first trimester of pregnancy. There is no general agreement on the value of submitting tissues from uterine evacuation in cases of miscarriage for histopathological examination. This study aimed to evaluate the role of histopathological examination in cases of first-trimester miscarriage.

Methods: This is a descriptive study was carried out over a period of 14 months, from January 2015 to March 2016, at Erbil Maternity Hospital. A total of 375 biopsies from patients admitted to maternity hospital with the diagnosis of the first trimester miscarriage and cases of spontaneous miscarriage were included in this study. The clinical data including age, parity, gestational age, clinical diagnosis, the method of evacuation, and other relevant information were collected and submitted for histopathological examination.

Results: Incomplete miscarriage was the commonest type of miscarriage and constituted $65.3 \%$ of the studied group and surgical evacuation was the most common method of termination. The histopathology reports confirmed the pregnancy in all patients and revealed retained product of normal pregnancy in $315(86.6 \%)$ cases, partial mole in $15(4 \%)$ patients, complete hydatidiform mole in one $(0.2 \%)$ case, decidual reaction in $21(5.6 \%)$ cases and no product of conception in $13(3.4 \%)$ cases .

Conclusion: Histopathological examination of the products of conception is an important method in detecting undiagnosed molar pregnancy that needs special follow-up and further management.
\end{abstract}

Keywords: Miscarriage; Histopathological examination; Molar pregnancy.

\section{Introduction}

Bleeding and early pregnancy failure represents common problems occurs in the first trimester of pregnancy. Histopathological examination of products of conception is a routine component of the management of patients with early pregnancy failure. ${ }^{1,2}$ The main reasons for doing a routine histopathological examination for the product of conception are: to prove the presence of an intrauterine gestation and to exclude undiagnosed gestational trophoblastic disease in the form of partial or complete hydatidiform mole. ${ }^{3}$ In addition, it is often hoped especially in the clinical setting of recurrent spontaneous miscarriage, that further diagnostic information explaining the underlying cause of the pregnancy loss may be obtained from such examination. ${ }^{4}$ However, there has been no systematic examination of the usefulness of routine examination of products of conception in spite of many cases reporting specific placental pathological findings associated with recurrent spontaneous miscarriage. ${ }^{5}$ The main role is to detect an ectopic pregnancy, which requires immediate further management, or a molar pregnancy, which needs special follow-up. ${ }^{4}$ Other reasons include detecting surgical complications, such as incomplete evacuation after pregnancy failure; determining the cause of recurrent miscarriage; or detecting unexpected fetal pathology. ${ }^{6}$ In addition from the

* Department of Pathology, College of Medicine, Hawler Medical University, Erbil, Iraq. 
medicolegal aspect, routine histopathologic examination of uterine products passed spontaneously or evacuated surgically or medically is beneficial in protecting obstetrician and gynecologist from medicolegal recrimination, but it is unclear whether this practice is medically justified. $^{3}$ An alternative approach is to examine the products only when there is a definite indication, such as when there is uncertainty about the diagnosis, either preoperatively or during surgery. ${ }^{4}$ In patients included in this study, the retained products of pregnancy passed spontaneously or evacuated surgically or medically are routinely subjected to histopathological examination. This study aimed to evaluate the role of histopathology in cases of first-trimester miscarriage and to determine whether clinically useful information can be obtained by such examination and to detect the frequency of such information.

\section{Methods}

In this descriptive observational study, 375 biopsies from patients admitted to the Erbil Maternity Hospital, from January 2015 to March 2016, with the diagnosis of first-trimester (5-12 weeks) abortions were examined. The clinical data including age, parity, gestational age, clinical diagnosis, the method of evacuation, and other relevant information were collected and submitted for histopathological examination. The samples were placed in $10 \%$ buffered formaldehyde and sent to the histopathology laboratory. The samples were undergoing gross examination before being embedded in paraffin blocks for further processing. The paraffin blocks were cut by a microtome into $4 \mathrm{~mm}$ sections and then stained with hematoxylin and eosin. The sections were examined microscopically by the same histopathologist who performed the gross examination. Two blocks were examined for each patient, and additional blocks were sometimes required to detect chorionic villi. During the microscopical examination, detecting fetal tissues, chorionic villi and trophoblasts confirm the intrauterine pregnancy in addition to other tissues, such as deciduae or secretory endometrium. Presence of deciduae with an Arias-Stella reaction suggest early intrauterine pregnancy, but this did not exclude the possibility of an ectopic pregnancy. Each report included a note about the absence or presence of trophoblastic diseases, such as molar pregnancy and the absence or presence of a malignant trophoblastic neoplasm. Analysis of data was done by the statistical package for the social sciences (version 19) computer software aided by Excel. A descriptive approach including frequency, percent, range, mean and S.D was done for the variables.

\section{Results}

During the period of this study, 375 biopsies of patients who were admitted to Maternity Teaching Hospital with the diagnosis of first-trimester miscarriage together with cases of spontaneous miscarriage admitted for emergency uterine evacuation were examined. Their mean age \pm SD was $26.4 \pm 7.5$ years, (range: 17-42 years) and mean parity \pm SD was $4.2 \pm 3.2$, (range: $0-7$ ). The clinical diagnosis on admission was incomplete miscarriage in $245(65.3 \%)$ patients, missed type in $98(26.1 \%)$ patients, blighted ovum in $22(5.8 \%)$ patients, and complete miscarriage in 10 $(2.6 \%)$ patients. In all uterine evacuation was done except for cases of complete miscarriage which was confirmed depending on clinical and ultrasound examinations; these women underwent no intervention as shown in Table 1. The histopathological results of 365 specimens (except of 10 specimens), were as follows: retained products of conception in 315 $(86.6 \%)$ patients; no products of conception in $13(3.4 \%)$ patients; complete molar pregnancy in $1(0.2 \%)$ patient; partial molar pregnancy in $15(4.1 \%)$ patient (Figure 1) and decidual tissue without 
The role of histopathological examination of .......

Zanco J. Med. Sci., Vol. 21, No. (3), December, 2017 https://doi.org/10.15218/zjms.2017.054

chorionic villi (Arias-Stella reaction) in $21 \quad(5.7 \%)$ patients as shown in Table 2.

Table 1: Types of abortion.

\begin{tabular}{lcc}
\hline Type of abortion & Number & (percentage) \\
\hline Incomplete & 245 & 65.3 \\
Missed & 98 & 26.1 \\
Blighted ovum & 22 & 5.8 \\
Complete & 10 & 2.6 \\
Total & 375 & 100 \\
\hline
\end{tabular}

Table 2: Histopathology report diagnosis.

\begin{tabular}{lcc}
\hline Histopathological diagnosis & Number & (percentage) \\
\hline Product of conception & 315 & 86.3 \\
Decidual reaction & 21 & 5.7 \\
Partial mole & 15 & 4.1 \\
No product of conception & 13 & 3.6 \\
Complete mole & 1 & 0.3 \\
Total & 365 & 100 \\
\hline
\end{tabular}

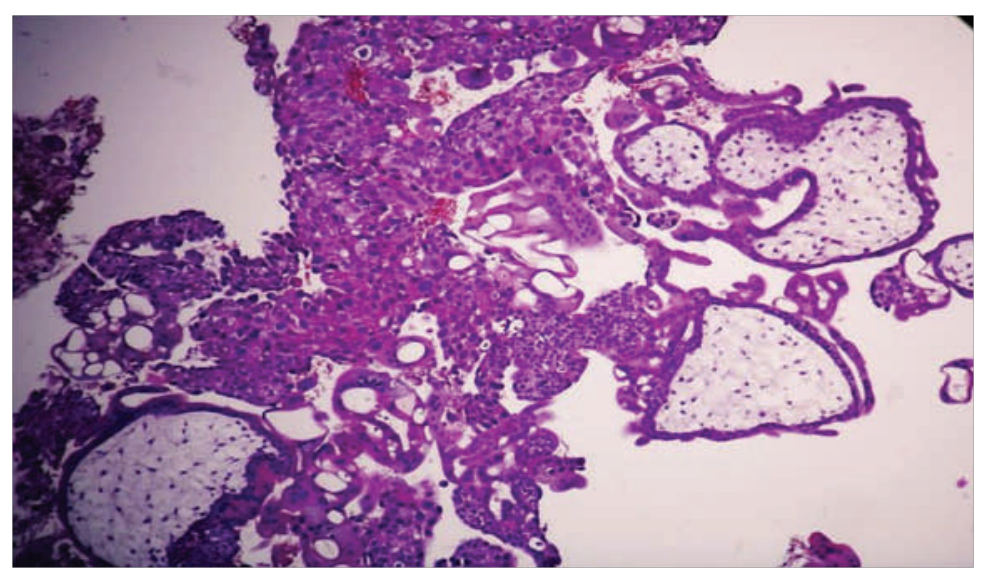

Figure 1: Chorionic villi with trophoblastic proliferation in partial mole. (H\&E 100x). 


\section{Discussion}

Miscarriage is a common condition in the first trimester of pregnancy, and like many other disorders, the accurate diagnosis is necessary for the management. But in some cases, it may be misdiagnosed when another condition that requires immediate treatment or long-term follow up, as an ectopic pregnancy or gestational trophoblastic disease exists. ${ }^{6}$ Many diagnostic tools were used to determine the type of miscarriage and to differentiate it from other conditions such as ultrasound, quantitative beta-human chorionic gonadotropin (beta-hCG) testing, and histopathologic examination of the uterine products. ${ }^{7}$ The tissue which passed by a spontaneous miscarriage or removed during the uterine evacuation is important to undergo histopathologic examination for detecting unsuspected conditions like molar or ectopic pregnancy and diagnosing surgical complications like the incomplete evacuation of the uterus. ${ }^{8}$ There is controversy regarding the practice of routine histopathologic examination of tissue removed during the miscarriage. Some authorities ${ }^{2,3,5,7,8}$ suggest that a sample of tissue from all uterine evacuations (either spontaneous or surgical/medical) should be submitted for histopathological assessment: first to confirm the pregnancy, second to exclude an ectopic pregnancy or gestational trophoblastic diseases and third to search for the causes of miscarriage. These researchers have tried to estimate the utility and cost-effectiveness of histopathologic examination of first-trimester miscarriage tissue. ${ }^{5,7}$ Some studies $^{3,5}$ have diagnosed other pathologies in tissue from first-trimester miscarriage such as exaggerated placental site, placental site trophoblastic nodule, and decidual tissue. The authors of these studies concluded that routine histopathologic examination of products of conceptions could lead to the diagnosis of important pathologies; more effectively identify ectopic pregnancies or infections than clinical or other laboratory criteria, and may reduce mortality. ${ }^{2,5}$ Other authors had recommended against the routine histopathological examination of tissues obtained from the first-trimester miscarriage. Heath et $\mathrm{al}^{6}$ reported only two $(0.13 \%)$ molar changes and two $(0.13 \%)$ tubal ectopic pregnancies among 1576 patients on histopathologic examination of the tissue removed during the therapeutic miscarriage or emergency uterine evacuation for a spontaneous miscarriage. $^{8} \quad$ Alsibiani ${ }^{4}$ reported $0.4 \%$ molar pregnancies and she concluded that it is not reasonable to perform histopathological examination routinely after all first-trimester miscarriage in their population. These authors recommended histopathology only for patients with an uncertain preoperative diagnosis or those in whom a small amount of tissue was collected or trophoblastic tissue was not identified during the evacuation. ${ }^{4,6}$ Histologic examination is a reliable method for diagnosing pathologic pregnancies, excluding hydatidiform mole histologically has important medical value, as it rules out the possibility of persistent trophoblastic disease or choriocarcinoma. ${ }^{8}$ To exclude molar pregnancy after miscarriage, the pathologist should examine all recovered material grossly and microscopically with at least five cassettes if the appearance suggests gestational trophoblastic disease. ${ }^{7,8}$ El-Halaby et $\mathrm{al}^{5}$ reported $3.1 \%$ cases of partial mole, $1.2 \%$ cases complete mole and $1.2 \%$ ectopic pregnancies, while Fram $^{2}$ reported 17\% partial mole from 293 biopsies. They concluded that routine histopathological evaluation of tissue removed during uterine evacuation of first-trimester miscarriage is very valuable as important findings like trophoblastic diseases and ectopic pregnancy can be diagnosed thus saving the lives of these patients. ${ }^{2,5}$ The incidence of gestational trophoblastic disease in the region is a factor that may affect the value of routine histopathologic examination of obtained tissues. In Asia, the incidence of 
hydatidiform mole is as high as 1 in 80 pregnancies, whereas in the western world, it is 1 in $500-1500$ pregnancies. ${ }^{9-11}$ The incidence of hydatidiform mole in Erbil Maternity Hospital is 1 in 314 pregnancies which is comparable to the incidence in the Middle East and Far East countries. ${ }^{12}$ This study, reported partial mole in 15 (4.1\%) biopsies and one $(0.2 \%)$ complete mole from 375 biopsies, all the cases were presented as spontaneous miscarriage. This indicates that still there are many patients who neglect the antenatal care.

\section{Conclusion}

Considering the findings of this study, histopathological assessment of the products of conception proved to be an important tool in detecting undiagnosed molar pregnancy that needs special follow-up and further management.

\section{Conflicts of interest}

The author reports no conflicts of interest.

\section{References}

1. Rosai J. Female Reproductive System, Rosai and Ackerman's Surgical Pathology, $10^{\text {th }}$ ed. Maryland Height, Missouri: Mosby; 2011. p. 1637-9.

2. Fram KM. Histological analysis of the products of conception following first trimester abortion at Jordan University Hospital. Eur J Obst Gyn Reproduc Biol 2002; 105(2):147-9.

3. Fulcheri E, Di CE, Ragni N. Histologic examination of products of conception at the time of pregnancy termination. Int J Gyn Obst 2003; 80(3):315-6.

4. Alsibiani SA. Value of histopathologic examination of uterine products after first-trimester miscarriage. BioMed Res Int 2014; 20(4):52-9.

5. El-Halaby O, AbdElaziz $O$, Elkelani $O$, Abo Elnaser M, Sanad Z, Samaka R. The value of routine histopathological examination of products of conception in case of first trimester spontaneous miscarriage. Tanta Medical Science J 2006; 1(4):83-8.

6. Heath V, Chadwick V, Cooke I, Manek S, MacKenzie IZ. Should tissue from pregnancy termination and uterine evacuation routinely be examined histologically? $\mathrm{Br} J$ Obst Gyn 2000; 107(6):727-30.

7. Tasci Y, Dilbaz S, Secilmis Q, Dilbaz B, Ozfuttu A, Haberal A. Routine histopathologic analysis of product of conception following first-trimester spontaneous miscarriages. J Obst Gyn Res 2005; 31(6):579-82.
8. Hinshaw K, Fayyad A, Munjuluri P. The management of early pregnancy loss. Revised Guideline no. 25. Green-top Guideline no. 25, Guidelines and Audit Committee of the Royal College of Obstetricians and Gynaecologists2006. (Available from: http://www.rcog.org.uk/womenshealth/clinical-guidance/ management-earlypregnancy-loss-green-top-25) Accessed July 5, 2015.

9. Sebire NJ, Seckl MJ. Gestational trophoblastic disease: current management of hydatidiform mole. Br Med J 2008; 337(67):453-8.

10. Steigrad SJ. Epidemiology of gestational trophoblastic diseases. Bailliere's Best Prac Res Clin Obst Gyn 2003; 17(6):837-47.

11. Al Mulhim AA. Hydatidiform mole: A study of 90 cases. J Family Community Med 2000; 7(3):57-61.

12. Al Alaf SK, Omer DI. Pattern of cases of gestational trophoblastic diseases among pregnant women admitted to the Maternity Teaching Hospital in Erbil. WSEAS Transactions on Biology and Biomedicine 2010; 7(3):190-9. 